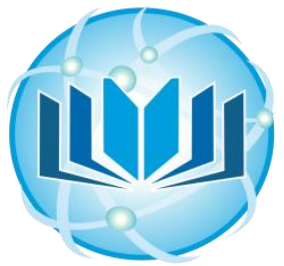

EDELWEISS PUBLICATIDNS IPEN ACCESS https://doi.org/10.33805/2639.6807.108

Volume 1 Issue 1 | PDF 108 | Pages 2

Cardiovascular Medicine

\title{
Initiation of Arterial Stenotic Thrombosis
}

\section{Mark IM Noble}

\section{Affiliation}

Department of Medicine and Therapeutics, Polwarth Building, Foresterhill, Aberdeen AB25 2ZH, University of Aberdeen, UK

*Corresponding author: Mark IM Noble, Department of Medicine and Therapeutics, Polwarth Building, Foresterhill, Aberdeen AB25 2ZH,

University of Aberdeen, UK, Tel: +44 1224 272000; E-mail: mimnoble@abdn. ac. uk

Citation: Noble MIM. Initiation of Arterial Stenotic Thrombosis (2018) Clinical Cardiol Cardiovascular Med 1: 9-10

Received: Aug 13, 2018

Accepted: Aug 17, 2018

Published: Aug 24, 2018

Copyright: ( 2018 Noble MIM. This is an open-access article distributed under the terms of the Creative Commons Attribution License, which permits unrestricted use, distribution, and reproduction in any medium, provided the original author and source are credited

\section{Introduction}

Current practice in arterial disease is to establish the site of stenosis, to dilate the stenosis with angioplasty or surgical bypass, and to try to maintain the integrity of the arterial lumen with stents. There are either bare stents or drug eluting stents which are more thrombogenic requiring long term dual antiplatelet therapy with its risk of increased bleeding. For coronary disease, this is called Percutaneous Coronary Intervention (PCI). A recent a study showed that heart stents for stable angina show no benefit over placebo [1,2]. It has also been shown that $12 \%$ of PCI patients are readmitted within 30 days [3]. A study of 60 day re-admission after PCI showed that among 1193 enrolled patients, $71(6.0 \%)$ underwent unplanned 60-day re-admission for unstable angina $(35.3 \%)$, chest pain $(21.1 \%)$, heart failure $(14.1 \%)$, and acute Myocardial infarction $(11.3 \%) ; 40.8 \%$ patients underwent repeated PCI. Drug eluting stents are associated with lower rates of restenosis but may be associated with later in-stent thrombosis, and/or bleeding at vascular access sites, intracranially, and in the upper gastrointestinal tract [4]. This is all very unsatisfactory. Have we have taken a wrong pathway in the treatment of arterial disease?

\section{Arterial Stenosis cause damaging increases in Shear Stress}

At an arterial narrowing (stenosis), the relationship between the pressure drop and the flow is both proportional and quadratic due to turbulence. A quantitative expression of a stenosis is the area ratio As/Ao, where As is the cross-sectional area of the stenosis and Ao is the cross-sectional are of the open, normal artery; this can be expressed as a percentage as (1- As/Ao)x100. As the same flow has to go through both the normal section, Ao and the much smaller As of the stenosis, the blood has to go faster, i. e. , velocity of blood flow increases; this is called convective acceleration. Think of watching a placid full river running into a gorge. So we envisage a mass of fluid accelerating into a narrowing of the artery exerting greater force, and just as objects in a river gorge feel force, so do blood cells in a stenosis. This effect is called shear stress. Shear stress applied to blood platelets activates them, initiating thrombus growth in such sites even in the absence of plaque rupture. This explains why coronary thrombosis occurs in stenosis in contrast to the lack of thrombosis in sites of endothelial damage but no narrowing.

\begin{abstract}
Shear stress at the normal arterial wall may be beneficial

An increase in flow through an artery, due to an increase in downstream demand, causes the artery to dilate. This is commonly known as Flow Mediated Dilatation (FMD) [5] and is commonly used to assess arterial endothelial function. It has been suggested that this effect of increased shear stress at the arterial wall is beneficial because the dilatation is mediated by nitric oxide [6], which is thought to be an anti atherothrombosis factor by Louis Ignarro (see his You-tube presentation), giving a scientific basis for the supposed beneficial effect of exercise [7].
\end{abstract}

\section{What happens in a stenosis?}

No-one seems to have queried the mechanism of predilection of arterial thrombosis to occur in stenosis. Here the analogy of the river gorge does not hold. Whereas objects in the gorge are swept downstream, in an arterial stenosis there occurs a platelet rich thrombus growth. When developing an experimental model of coronary arterial thrombosis, we all experienced the fact that endothelial damage alone does not produce thrombosis. One has to apply a stenosis to set off thrombus growth [812]. Why has this fact been ignored? Why is current drug therapy based on the results of platelet aggregation only in response to endothelial damage? Is it not likely that there is something about the presence of arterial narrowing and the hemodynamics of stenosis that is the correct target for therapy? Platelets within a stenosis are subjected to force and turbulence and these factors activate them. The response of platelet activation is release of serotonin which is packed into their dense granules. Reduction of secretion of these dense granules is associated with marked protection from the development of arterial thrombosis, inflammation and neointimal hyperplasia after vascular injury [13]. The reason for this is that platelets are also activated by serotonin through the $5 \mathrm{HT} 2 \mathrm{~A}$ receptor, so that serotonin released by stenosis shear stress activates more platelets which release more serotonin, setting up the well-known serotonin (in addition to other feedback mediators) positive feedback cycle [14]. The importance of serotonin in this platelet feedback process is its abolition by 5 HT2A receptors, for which at least 20 references are available [11,12]. 


\section{Imaging of arterial stenosis}

Modern imaging of internal organs using magnetic resonance, yields images with much greater detail of the structure of stenosis, including complex ones at artery bifurcations together with the accompanying blood velocity patterns [15-17]. This is combined with computational fluid dynamic measurements and multi-scale modeling [18-20] with which one perceives the exciting possibility that the force applied to each platelet might be calculated. Leading to a prediction of which platelets are likely to be activated by the shear stress and release serotonin to trigger thrombus growth. Already, these techniques have been useful when applied to the study of atheromatous lesion growth and post stenting disease. Nevertheless, in practical cardiology today, it is predicted that the altered hemodynamics of stenosis, which have a variety of patho-antomical features and abnormal blood flow patterns, all activate platelets if the increase in shear stress and turbulence are sufficiently great.

Can arterial stenosis-induced arterial thrombosis be treated specifically?

Since stenosis thrombus growth is serotonin dependent, that treatment of arterial disease with 5HT2A receptor antagonists is urgently required. The additional benefit of this approach is that, there being no serotonin in wounds, the prediction is that there will be no bleeding complications, as occurs with dual antiplatelet therapy [4]. There is at least one of these drugs that has shown no change in bleeding time in patients $[12,21,22]$.

The proposed treatment for the future is that patients with symptoms suggestive of arterial disease be prescribed a 5HT2A antagonist. If the symptoms are acute. i. e. , possible acute coronary syndrome, stroke, leg ischemia, the drug should be given intravenously. If not acute, the patient would be given a course of oral 5HT2A antagonist. While the patient is thus protected, the patient undergoes investigation, e. g. , angiography, MRI imaging [15-17], exploratory surgery, which will induce only normal operative bleeding. Any stenosis that is shown, resting, or upon stress testing, may then undergo an appropriate procedure to remove stenosis. Post intervention treatment will be chronic administration of a 5HT2A antagonist with no fear of excessive bleeding, only normal bleeding.

\section{References}

1. Al-Lamee R, Thompson D, Hakim-Moulay Dehbi, John Davies, Thomas Keeble, et al. Percutaneous coronary intervention instable angina (ORBITA): A double- blind, randomised controlled trial (2018) Lancet 391: 31-40. https://doi.org/10.1016/S0140-6736(17)32714-9

2. Jacqui Wise. Heart stents for stable angina show no benefit over $\begin{array}{llll}\text { placebo } & \text { (2017) } & \text { BMJ } & \text { 359: }\end{array}$ https://doi.org/10.1136/bmj.j5076

3. Tripathi A, Abbott JD, Fonarow GC, Khan AR, Barry NG $4^{\text {th }}$, et. al. Thirty-Day Re-admission Rate and Costs After Percutaneous Coronary Intervention in the United StatesA National Readmission Database Analysis (2017) Circ Cardiovasc Interv 10 : https://doi.org/10.1161/CIRCINTERVENTIONS.117.005925

4. Bhala N, Jaspal S Taggar, Praveen Rajasekhar and Amitava Banerjee. Anticipating and managing bleeding complications in patients with coronary stents who are receiving dual antiplatelet treatment (2011) BMJ 343: 4264 https://doi.org/10.1136/bmj.d4264

5. Markos, F, Ruane O'Hora, T and Noble MIM. What is the mechanism of flow mediated arterial dilatation? (2013) Clin Exp Pharmacol Physiol 40: 489-494. https://doi.org/10.1111/1440$\underline{1681.12120}$
6. Snow HM, Markos F, O'Regan D and Pollaock K. Characteristics of arterial wall shear stress which causes endothelium-dependent vasodilatation in the anaesthetized $\operatorname{dog}$ (2001) J Physiol 531: 843848. https://dx.doi.org/10.1111\%2Fj.1469-7793.2001.0843h.x

7. Napoli C, Ignarro SW, de Nigris F, Lerman LO, Rossi L, et al. Long-term combined beneficial effects of physical training and metabolic treatment on atherosclerosis in hypercholesterolemic mice (2004) Proc Natl Acad Sci 101: 8797-8802. https://doi.org/10.1073/pnas.0402734101

8. Folts JD and Rowe GG. Cyclical reductions in coronary blood flow in coronary arteries with fixed partial obstruction and their inhibition with aspirin (1974) Fed Proc 33: 413.

9. Folts JD, Crowell EB and Rowe GG. Platelet aggregation in partially obstructed vessels and its elimination with aspirin (1976) Circ 54: 365-370. https://doi.org/10.1161/01.CIR.54.3.365

10. Folts JD. Experimental arterial platelet thrombosis, platelet inhibitors, and their possible clinical relevance (1982) Cardiovasc Rev Rep 3: 370-382.

11. Torr S, Noble MIM and Folts JD. Inhibition of acute platelet thrombosis formation in stenosed canine coronary arteries by the specific serotonin 5HT2 receptor antagonist ritanserin (1990) Cardiovasc Res 24: 465-470. https://doi.org/10.1093/cvr\%2F24.6.465

12. McAuliffe SJG, Snow HM, Cox B, Smith CTT and Noble MIM. Interaction between the effect of 5-hydroxytryptamine and adrenaline on the growth of platelet thrombi in the coronary artery of the anaesthetised dog (1993) Brit J Pharmacol 109: 405410. http://dx.doi.org/10.1111/j.1476-5381.1993.tb13583.x

13. King SM, McNamee RA, Houng AK, Patel R, Brands M et al. Platelet dense granule secretion plays a critical role in thrombosis and subsequent vascular remodeling in atherosclerotic mice
(2009)
Circ
120
$785-791$. https://doi.org/10.1161/CIRCULATIONAHA.108.845461

14. Golebiewska EM and Poole AW. Platelet secretion: From haemostasis to wound healing and beyond (2015) Blood Rev 29: 153-162. https://doi.org/10.1016/j.blre.2014.10.003

15. Steinman DA. Image-Based Computational Fluid Dynamics Modeling in Realistic Arterial Geometries (2002) Annals Biomed Eng 30: 483-497. https://doi.org/10.1114/1.1467679

16. Long Q, Xu XY, Ariff B, Thom SA and Hughes AD. Reconstruction of blood flow patterns in a human carotid bifurcation: A combined CFD and MRI study (2000) JMRI 11: 299-311. 2586(200003)11:3\%3C299::AID-JMRI9\%3E3.0.CO;2-M

17. Long Q, Xu XY, Nourne $M$ and Griffith TM. Numerical study of blood flow in an anatomically realistic aorto-iliac bifurcation generated from MRI data (2000) Magn reson med 43: 565-576. https://doi.org/10.1002/(SICI) 1522 2594(200004)43:4\%3C565::AID-MRM11\%3E3.0.CO;2-L

18. Thorne BC, Bailey AM and Peircs SM. Combining experiments with multi-cell agent-based modeling to study biological tissue patterning (2007) Brief Bioinf 8: 245-257. https://doi.org/10.1093/bib/bbm024

19. Sloot PMA and Hoekstra AG. Multi-scale modelling in computational biomedicine (2010) Brief Bioinf 11: 142-152. https://doi.org/10.1093/bib/bbp038

20. Zhang Y, Barocas VH, Berceli SA, Clancy CE, Eckmann DM et al. Multi-scale Modeling of the Cardiovascular System: Disease Development, Progression, and Clinical Intervention (2016) Ann Biomed Eng 44: 2642-2660. https://doi.org/10.1007/s10439-016$\underline{1628-0}$

21. Noble MIM, Ford F, Cameron G, and Drake-Holland AJ. The Novel Anti-Thrombotic Drug with No-Bleeding Excess (2017) J Cardiol \& Cardiovasc Ther 6: 1-6. DOI: 10.19080/JOCCT.2017.06.555684

22. Noble MIM and Drake-Holland AJ. Preservation of haemostasis with anti-thrombotic serotonin antagonism (2017) J Hematol Clin Res 1: 19-25. https://dx.doi.org/10.29328/journal.jhcr.1001004 